\title{
Extended polyglutamine selectively interacts with caspase-8 and -10 in nuclear aggregates
}

\author{
M U', T Miyashita*,1, Y Ohtsuka ${ }^{1}$, Y Okamura-Oho', \\ Y Shikama ${ }^{1}$ and M Yamada ${ }^{1}$ \\ 1 Department of Genetics, National Children's Medical Research Center, \\ 3-35-31, Taishido, Setagaya, Tokyo 154-8509, Japan \\ * Corresponding author: T Miyashita, Department of Genetics, National \\ Children's Medical Research Center, 3-35-31, Taishido, Setagaya, Tokyo \\ 154-8509, Japan. Tel: +81-3-3414-8121; Fax: +81-3-3414-3208; \\ E-mail: tmiyashita@nch.go.jp
}

Received 30.5.00; revised 18.10.00; accepted 21.11.00 Edited by DR Green

\begin{abstract}
A growing number of inherited neurodegenerative disorders, including Huntington's disease, have been shown to be caused by the expansion of CAG/polyglutamine repeats. The molecular mechanism underlying these disorders, however, has yet to be clarified. We and others previously demonstrated that caspase-8 was activated by proteolysis in association with the expression of extended polyglutamine. Here, we further analyzed the selectivity of caspases in the process mediated by extended polyglutamine. Among upstream caspases, caspase-10, a close homolog of caspase-8, was also proteolytically activated, but caspase-9 was not. Caspase-8 and -10 were recruited into nuclear aggregates of extended polyglutamine, where at least a fraction of these caspases was converted to the activated forms. Caspase-8 and -10 were co-immunoprecipitated with polyglutamine only when the polyglutamine was pathologically extended, whereas caspase-2, $-3,-6,-7$ and -9 were not co-immunoprecipitated with polyglutamine regardless of its size. A dominant-negative form of caspase-8 with a mutation at the catalytic cysteine residue inhibited polyglutamine-mediated nuclear apoptotic phenotype. These results suggest that caspase- 8 and -10 are autoactivated as a result of close proximity of the proforms of these molecules that occurs due to aggregate formation, which reveals a novel toxic gain-offunction mechanism for the pathogenesis of CAG-repeat disorders. Cell Death and Differentiation (2001) 8, 377-386.
\end{abstract}

Keywords: polyglutamine; caspase; CAG repeats; Huntington's disease

Abbreviations: DISC, death-inducing signaling complex; DRPLA, dentatorubral pallidoluysian atrophy; GFP, green fluorescent protein; HD, Huntington's disease; PML, promyelocytic leukemia protein; TC, tetracycline; TRITC, tetramethylrhodamine isothiocyanate; z-VAD-fmk, carbobenzoxy-Val-Ala-Asp-fluoromethyl ketone

\section{Introduction}

To date, eight neurodegenerative disorders including Huntington's disease (HD) and dentatorubral pallidoluysian atrophy (DRPLA), have been shown to be caused by the expansion of CAG repeats. ${ }^{1,2}$ The CAG repeats are located in the coding regions of the respective responsible genes and are translated into polyglutamine. These disorders, collectively called CAG-repeat disorders or polyglutamine diseases, are characterized by neuron death in the region specific to each disease. ${ }^{3}$ The molecular mechanism underlying these disorders has yet to be clarified. However, accumulating evidence suggests that caspases, at least in part, are involved in the neurodegeneration.

Caspases constitute a family of cysteine proteases that play important roles in the execution of apoptosis. Each of these enzymes is synthesized as a zymogen and proteolytically activated by its own active form or other members of caspases. ${ }^{4}$ Involvement of caspases in CAGrepeat disorders are supported by three groups of observations: (i) Some of the products of the genes responsible for CAG-repeat disorders are substrates for caspases, and their cleaved fragments carrying extended polyglutamine tend to easily form aggregates; ${ }^{5-8}$ (ii) an activated form of caspases has been detected in the affected regions of the brains of patients and of model animals as well as in cultured cells of experimental systems; ${ }^{9-11}$ and (iii) inhibition of caspases slows cell death or suppresses the apoptotic nuclear phenotype in model animals as well as in in vitro experimental systems. $^{10,12}$

We previously demonstrated that expression of extended polyglutamine sequentially activated caspase- 8 and then caspase-3. ${ }^{9}$ Sánchez et al. ${ }^{10}$ also reported detection of the proteolytically activated form of caspase- 8 in the affected brain region of HD patients. Caspase-8 (MACH/FLICE/ Mch5) was originally cloned as a protein that interacts with FADD (MORT1), a mediator of Fas (CD95/APO-1)-induced apoptosis, or as a component of death-inducing signaling complex (DISC). ${ }^{13,14}$ The targeted disruption of the caspase- 8 gene is lethal in utero and the TNF receptors, Fas, and DR3 failed to induce cell death in embryo fibroblasts containing a disrupted caspase- 8 gene. ${ }^{15}$

To analyze the selectivity of caspases during the process of cell death mediated by extended polyglutamine and to further investigate the mechanism of caspase activation, we have analyzed the interaction of polyglutamine and various caspases. We show here that polyglutamine preferentially interacts with and activates caspase- 8 and its close homolog, caspase-10 (Mch4/ FLICE2), ${ }^{16,17}$ and suggest a novel caspase-8- or -10mediated cell death pathway alternative to Fas-mediated apoptosis. 


\section{Results}

\section{Among initiator caspases, caspase-8 and -10 are proteolytically activated by polyglutamine, but caspase-9 is not}

We and others previously demonstrated that caspase- 8 was cleaved and activated in association with the expression of extended polyglutamine., ${ }^{9,10}$ In the present study, we first examined whether caspase-10, a close homolog of caspase8 , was also proteolytically activated during this process. To address this question, we utilized the TC-controlled polyglutamine expression system in IGROV cells as described previously. ${ }^{9}$ IGROV-EQ19 and IGROV-EQ56 cells express 19- and 56-stretches of polyglutamine fused with the enhanced green fluorescent protein (EGFP) (EGFP-polyQ ${ }_{19}$ and EGFP-poly $Q_{56}$ ), respectively, when TC is removed from the culture medium. The cleaved products of caspase- 8 and -10 were detected at $72 \mathrm{~h}$ after withdrawal of TC only in cells expressing extended polyglutamine (Figure 1A, top and middle panels). Another apical caspase that plays an important role in apoptosis is caspase-9 (MCH6), which is activated by Apaf1 and cytochrome $c$ released from mitochondria. ${ }^{19}$ In contrast to caspase- 8 and -10 , the amount of the proform of caspase- 9 remained constant and the cleaved form was not detected by $72 \mathrm{~h}$ after the TC withdrawal (Figure 1A, bottom panel). The caspase-9 antibody used in this experiment was confirmed to react with the processed form of caspase- $9^{20}$ by the use of an engineered construct, caspase-9 $9 \mathrm{C}$ (amino acids $1-315$ ), in addition to
A

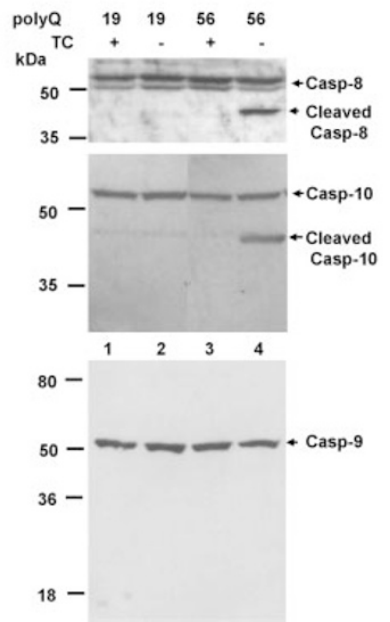

B

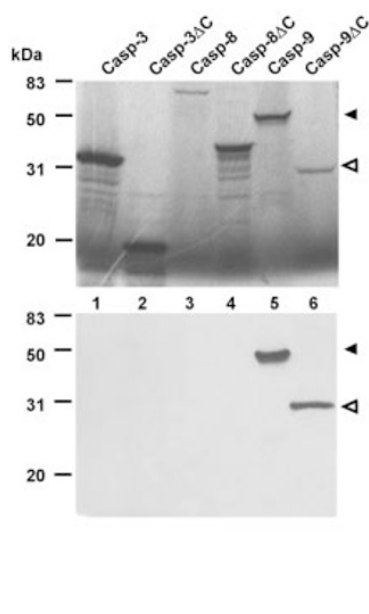

Figure 1 Extended polyglutamine activated caspase-8 and -10 , but not caspase-9. (A) IGROV-EQ19 and IGROV-EQ56 cells were incubated in the presence or absence of TC. Cell lysates were prepared at $72 \mathrm{~h}$ and Western blot analyses were performed using an anti-caspase-8 (upper panel), anticaspase-10 (middle panel), or anti-caspase-9 antibody (lower panel). (B) Proforms and processed forms of caspases were translated in vitro in the presence (upper panel) or absence (lower panel) of L- $\left[{ }^{35} \mathrm{~S}\right]$-methionine. Translated products were subjected to SDS-PAGE followed by autoradiography (upper panel), or Western blotting using the anti-caspase- 9 antibody (lower panel). Closed and open arrowheads indicate procaspase- 9 and processed caspase-9, respectively the intact form (Figure 1B). The antibody had no cross reactivity with the intact or processed forms of caspase-3, -8, -6 , or -7 (Figure 1B, and data not shown). These results indicate that the caspase-9-mediated apoptotic pathway is not involved in polyglutamine-induced cell death.

\section{Caspase-8 and -10 colocalize with nuclear aggregates of extended polyglutamine}

Initiator caspases such as caspase-8 and -9 were reported to be autoactivated by oligomerization of the molecules ${ }^{21,22}$ If procaspase-8 coaggregates with polyglutamine, caspase-8 molecules are brought into close proximity and may cleave one another. To test this hypothesis, we first analyzed the subcellular localization of caspases- 8 and -10 in the presence or absence of nuclear aggregates of extended polyglutamine. By immunostaining, caspase-8 and -10 were detected primarily in the cytoplasm (Figure 2B,E, thin arrows). However, in cells with nuclear aggregates of extended polyglutamine, these caspases were primarily detected in the nucleus, and co-localized with the aggregates (Figure 2B, $\mathrm{E}$, thick arrows, and Figure $2 \mathrm{C}, \mathrm{F}$ ). The specificity of the results was demonstrated by the absence of co-localization of caspase- 3 and $\mathrm{Bcl}-2$ with the aggregates (Figure $2 \mathrm{G}-\mathrm{L}$ ). This also indicates that the nuclear signals in Figure 2B, E are not due to the leakage of green fluorescence of GFP. polyglutamine.
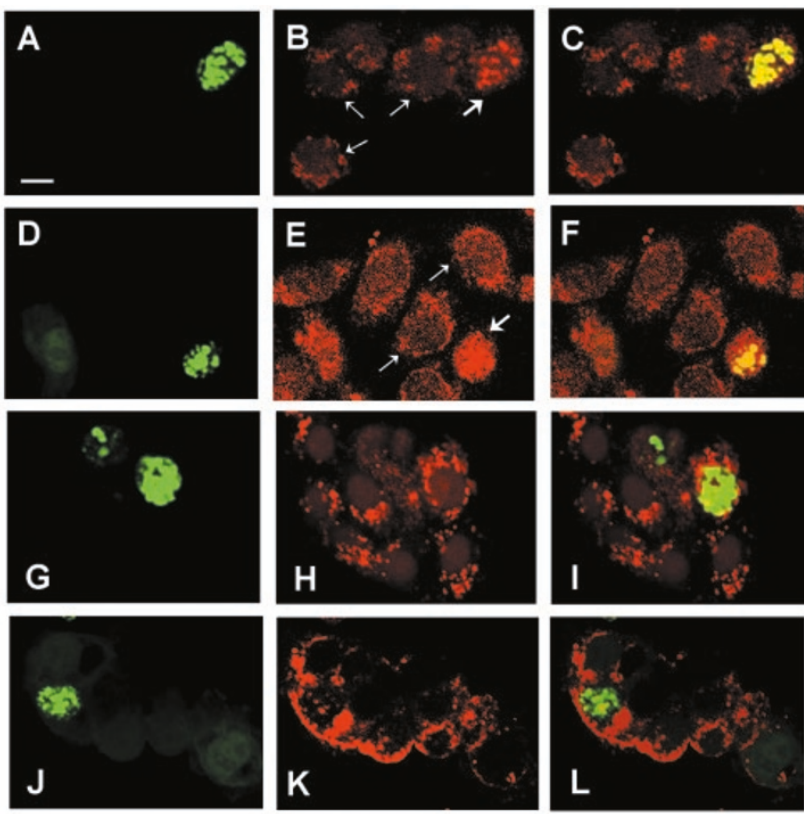

Figure 2 Co-localization of caspase-8 and -10 with nuclear aggregates of extended polyglutamine. IGROV-EQ56 cells were incubated in the absence of TC for 3 days to induce EGFP-poly $Q_{56}$ expression, and subjected to immunostaining followed by confocal microscopy. $(\mathbf{A}, \mathbf{D}, \mathbf{G}, \mathbf{J})$ Green fluorescence shows the presence of EGFP-poly ${ }_{56}$. $(B, E, H, K)$ Red fluorescence indicates the localization of endogenous caspase-8, caspase-10, caspase-3, and $\mathrm{Bcl}-2$, respectively, by immunostaining with the respective antibodies. $(\mathbf{C}, \mathbf{F}, \mathrm{I}, \mathrm{L})$ Merged images of the left two panels. Bar: $10 \mu \mathrm{m}$ 


\section{Caspase- 8 is activated in nuclear aggregates}

To test whether caspases were activated in the nuclear aggregates, we raised antibodies that specifically react with a processed form of caspase-8 or -9 . It has been demonstrated that caspase- 8 and -9 are proteolytically cleaved at Asp374 and Asp315, respectively. ${ }^{20,23}$ Hexapeptides that precede the cleavage sites as well as an amino-terminal cysteine residue to allow coupling to keyhole limpet hemocyanin were synthesized and used as immunogens. Antisera that had been shown to have high titers against the respective antigens in ELISA were purified by immunoadsorption to the same peptides. We then analyzed the specificity of each antiserum with GST- or $\mathrm{His}_{6}$-tagged proteins produced in $E$. coli (Figure $3 A, B)$. The anti-caspase- $8 \Delta C$ antiserum recognized GST-fused caspase- $8 \Delta \mathrm{C}$, which corresponds to the processed form, but not full-length caspase-8 or caspase$8 \Delta \mathrm{N}$ (Figure $3 \mathrm{C}$, lanes $1-3$ ). Anti-caspase-9 $9 \Delta \mathrm{C}$ also reacted with the pseudo-processed form but not with caspase- $9 \Delta \mathrm{N}$ (Figure 3D, lanes 4 and 5). These antisera did not react with other species of caspases, including caspase-7 (Figure 3D, and data not shown). Thus, the two antisera could be used to detect processed forms of caspase- 8 and -9 .

A

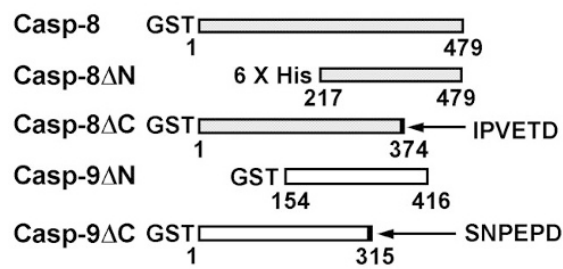

B
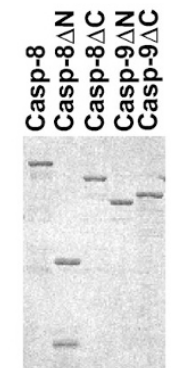

C
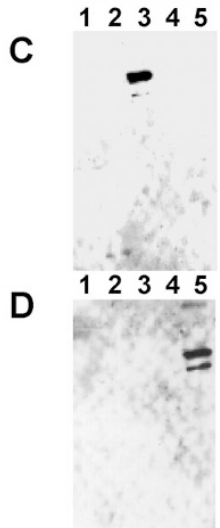

Figure 3 The specificity of antisera raised against the C-terminal cleavage site of caspase-8 and -9. (A) Schematic diagrams of recombinant GST- or $\mathrm{His}_{6}$-caspases produced in E. coli. The numbers below the boxes indicate the position of the amino acids counted from the initiation methionine. Peptides used to generate antisera corresponding to the $\mathrm{C}$-terminal amino acids of the cleaved forms are indicated with the single letter code. (B) Six hundred nanograms of the purified fusion proteins were analyzed by electrophoresis on $10 \%$ SDS-polyacrylamide gels, followed by Coomassie Brilliant Blue staining. (C,D) Fifty nanograms of the indicated proteins were subjected to SDS PAGE, followed by Western blotting with anti-caspase-8AC (C) or anticaspase-9 $9 \Delta$ C (D) antibody
We then applied the two antisera to the cells expressing extended polyglutamine and forming nuclear aggregates as in the experiments shown in Figure 2. Activated caspase-8 was detected in nuclear aggregates containing extended polyglutamine (Figure 4A-C). However, caspase-8 was not activated in cells without nuclear aggregates even if they express extended polyglutamine homogeneously throughout the cell (Figure 4C, arrow). In contrast, activated caspase- 9 was not detected in cells with nuclear aggregates (Figure 4D-F). Staining with anticaspase- $9 \Delta \mathrm{C}$ antiserum did detect activated caspase- 9 in Jurkat cells growing in the presence of staurosporine (STS) but not in the cells without the treatment (Figure 4G, $H$ ). In addition, processed forms of caspase-9 were detected in Jurkat cell lysate when treated with STS by immunoblotting (Figure 4l, lane 4), indicating that the green fluorescence in Figure $4 \mathrm{H}$ indeed demonstrates cleaved caspase-9. However, the smaller form of the processed caspase- 9 was not detected by the conventional anti-caspase-9 used in Figure 1 (Figure 4I, lane 2). Altogether, failure to detect activated caspase- 9 in nuclear aggregates is not due to the inability of anti-caspase- $9 \Delta \mathrm{C}$ to react with its antigen in immunostaining. Therefore, based on these results, we conclude that at least a fraction of caspase-8 in the nuclear aggregates is converted into its activated form.

\section{Polyglutamine preferentially interacts with caspase-8 in vivo}

To further demonstrate the selectivity of caspases in the polyglutamine-induced processing, we performed immunoprecipitation experiments. After various caspases were tagged with a FLAG-epitope, they were transiently expressed in 293 cells together with GFP-tagged polyglutamines. Extended polyglutamine (71 repeats) easily formed large aggregates in the nucleus, whereas polyglutamine of a normal size range (19 repeats) was distributed homogeneously both in the nucleus and cytoplasm (Figure 5A). Immunoprecipitation experiments with the anti-FLAG antibody followed by detection by Western blotting with the anti-GFP antibody clearly showed that extended polyglutamine was specifically co-precipitated with caspase-8 among the caspases tested, and that polyglutamine with a normal size range was not (Figure $5 \mathrm{~B})$. In this experiment, caspase- 8 had to have a mutation at the cysteine residue in the active center (C360S) in order to obtain a high level of expression similar to those of other caspases as reported previously. ${ }^{13}$ Caspase- 6 and -9 were not co-precipitated with polyglutamine regardless of the length of the polyglutamine. This was not due to a difference in the expression levels of the caspases, as demonstrated by Western blotting without immunoprecipitation (Figure 5C).

\section{Polyglutamine selectively interacts with endogenous caspase- 8 and -10}

To explore the interaction under more physiological conditions, we next examined whether extended polyglutamine 

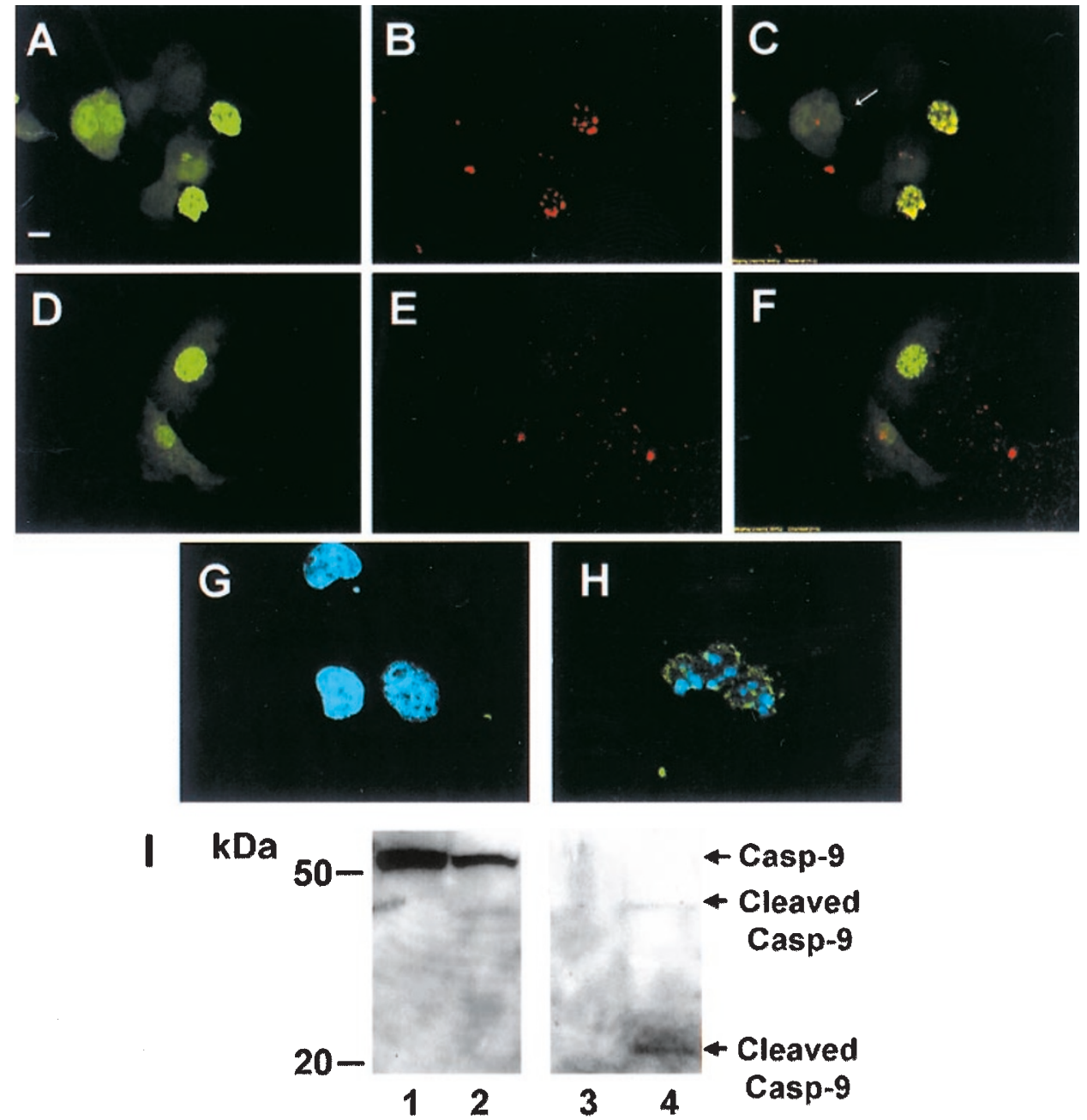

Figure 4 Activated forms of caspase-8 in nuclear aggregates. IGROV-EQ56 cells were incubated in the absence of TC for 3 days to induce EGFP-polyQ ${ }_{56}$ expression, and subjected to immunostaining followed by confocal microscopy. (A,D) Green fluorescence indicates the presence of EGFP-poly $Q_{56}$; $(\mathbf{B}, \mathbf{E})$ Red fluorescence indicates the localization of the active form of caspase-8 and -9 detected with the anti-caspase-8 $8 \mathbf{C}(\mathbf{B})$ or anti-caspase-9 $9 \mathbf{C}$ (E) antibodies. (C,F) Merged images of the left two panels. Jurkat cells were cultured in the absence $(\mathbf{G})$ or presence of $500 \mathrm{nM}$ staurosporine $(\mathbf{H})$ for $6 \mathrm{~h}$. Cells were then stained with the anti-caspase- $9 \Delta \mathbf{C}$ antibody, and with Hoechst 33342 for counterstaining of the nuclei. Panels $\mathbf{G}$ and $\mathbf{H}$ are shown as merged images of activated caspase-9 (green) and nuclei (blue). (I) Jurkat cells were incubated in the absence (lanes 1 and 3) or presence of $500 \mathrm{nM}$ staurosporine (lanes 2 and 4 ) for $6 \mathrm{~h}$ and Western blot analyses were performed using anti-caspase-9 (lanes 1 and 2) and anti-caspase-9 $4 \mathrm{C}$ antibodies (lanes 3 and 4 )

interacts with endogenous caspases. Using a conditional expression system employing IGROV cells, endogenous caspase-8 was confirmed to be co-immunoprecipitated with extended polyglutamine but not with polyglutamine of a normal size range (Figure $6 \mathrm{~A}$ ). Interestingly, most molecules obtained by co-immunoprecipitation were the processed form rather than the proform, which suggests that procaspase-8 recruited into the aggregates with polyglutamine rapidly undergoes proteolysis. With the converse combinations of antibodies in immunoprecipitation and Western blotting, antibodies against caspase-8 or -10 pulled down extended polyglutamine, but not polyglutamine of a normal size range (Figure 6B). On the other hand, endogenous caspase-2, -3, and -7 were not co-immunoprecipitated with extended polyglutamine, further demonstrating the specificity of the caspase in the interaction with polyglutamine (Figure $6 C-G$ ).
Anti-caspase- 3 and -7 antibodies successfully immunoprecipitated the respective caspases (Figure 6C,D, right panels) and anti-caspase-2, -3 , and -7 reacted with the respective antigens when immunoblotted (Figure $6 \mathrm{C}-\mathrm{G}$ ). Therefore, the failure to detect interaction of polyglutamine with these caspases was not due to the inability of the antibodies to react with their antigens. All the data presented herein demonstrate that caspase- 8 and -10 selectively interact with polyglutamine.

\section{Indirect interaction of polyglutamine with the caspases}

We then examined with an in vitro binding assay whether polyglutamine and caspases directly interact with each other. GST-polyglutamine fusion proteins were generated in E. coli 
A
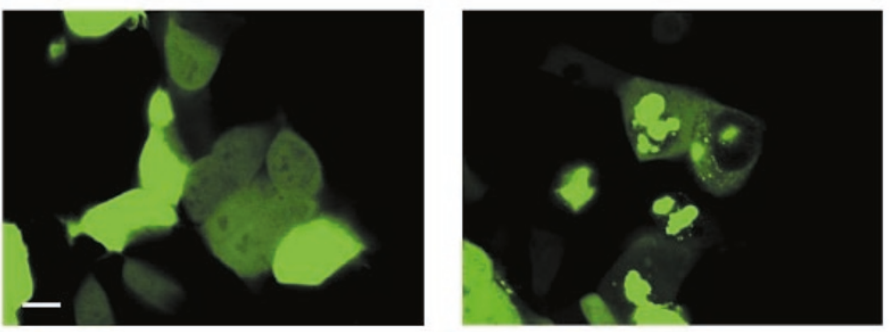

B
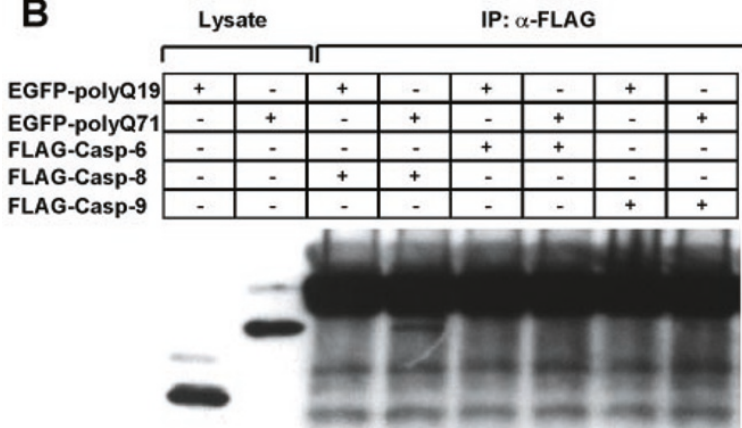

1

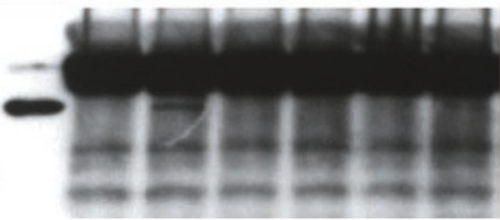

23

4

5

7

Figure 5 Interaction between polyglutamine and caspases. (A) Expression of EGFP-polyQ 19 (left panel) or EGFP-polyQ 71 (right panel) in 293 cells $72 \mathrm{~h}$ after transfection was observed by confocal microscopy. Bar: $10 \mu \mathrm{m}$. (B,C) The interaction was assayed by immunoprecipitation followed by Western blotting. 293 cells were transfected with the indicated combinations of expression vectors for GFP-tagged polyglutamine and FLAG-tagged caspases. Cell lysates were prepared at $72 \mathrm{~h}$ after transfection and subjected to immunoprecipitation (IP) with the anti-FLAG antibody. The immunoprecipitates (B, lanes $3-8$ ) as well as an aliquot of the original lysates (B, lanes 1 and 2, and $\mathbf{C}$ ) were analyzed by immunoblotting with the anti-GFP (B) or anti-FLAG (C) antibody with ECL-based detection

and purified by affinity chromatography (Figure 7A). They were then incubated with in vitro-translated caspases labeled with $\left[{ }^{35} \mathrm{~S}\right]-$ methionine. Neither radio-labeled caspase-8 nor caspase- 9 interacted with GST-fused polyglutamines regardless of its length under conditions in which GST-Bcl-2 was readily associated with Bax, a known heteromeric binding partner of $\mathrm{Bcl}-2$ (Figure 7B). Therefore, it is likely that polyglutamine binds to caspase- 8 and -10 via a third adaptor molecule(s).

\section{Dominant negative caspase-8 effectively inhibits polyglutamine-mediated apoptosis}

To further examine the involvement of caspase- 8 in polyglutamine-mediated apoptosis, we made a construct, pFLAGCasp8(C/S), encoding protease-dead caspase-8 that has a dominant negative effect on the wild-type caspase-8. ${ }^{13}$ As reported earlier, a pan-caspase inhibitor, z-VAD-fmk, had no effect on the aggregate formation of polyglutamine, while it significantly, although not completely, inhibited apoptosis (Table 1). ${ }^{9}$ Caspase-8(C/S) also inhibited apoptosis to a similar extent, although, again, had no effect on aggregate formation. This implies that caspase- 8 is a major mediator of polyglutamine-mediated apoptosis.

\section{Discussion}

Two major pathways lead to the activation of effector caspases and eventually to cell death via apoptosis. One involves the release of cytochrome $c$ from mitochondria, which, together with Apaf-1 and dATP, activates caspase-9. Another pathway involves DISC-formation, including caspase-8, at the site of death receptors such as Fas. Therefore, among at least fourteen members of the caspase family reported to date, caspase- 8 and -9 are the pivotal apical caspases. This is also supported by experiments showing that the targeted disruption of each caspase resulted in seriously defective phenotypes caused by the failure to induce cell death. ${ }^{15,24,25}$ Here we have demonstrated the possibility that caspase-8, but not -9 , plays an important role in polyglutamine-induced cell death. However, the role of caspase-9 is not completely ruled out, because it was recently reported that caspase- 9 can be activated without proteolysis, and that its activity is also regulated by phosphorylation. ${ }^{20,26}$

We also demonstrated here for the first time that caspase-10 also interacts with and is activated by extended polyglutamine. This finding is intriguing but not unexpected because caspase-10 (FLICE2) has a significant homology over its entire sequence (28\% identity) to caspase-8. ${ }^{17}$ The importance of caspase-10, at least in lymphocyte homeostasis, has been demonstrated recently by the discovery of inherited caspase-10 mutations in autoimmune lymphoproliferative syndrome. ${ }^{27}$ However, the similar extents of inhibition of apoptosis by z-VAD-fmk and caspase-8(C/S) may imply that caspase-10 is not absolutely required for polyglutamine-induced apoptosis. In any case, since GST-fused polyglutamine did not interact with in vitro-translated caspase-8, it is more likely that these two 
A

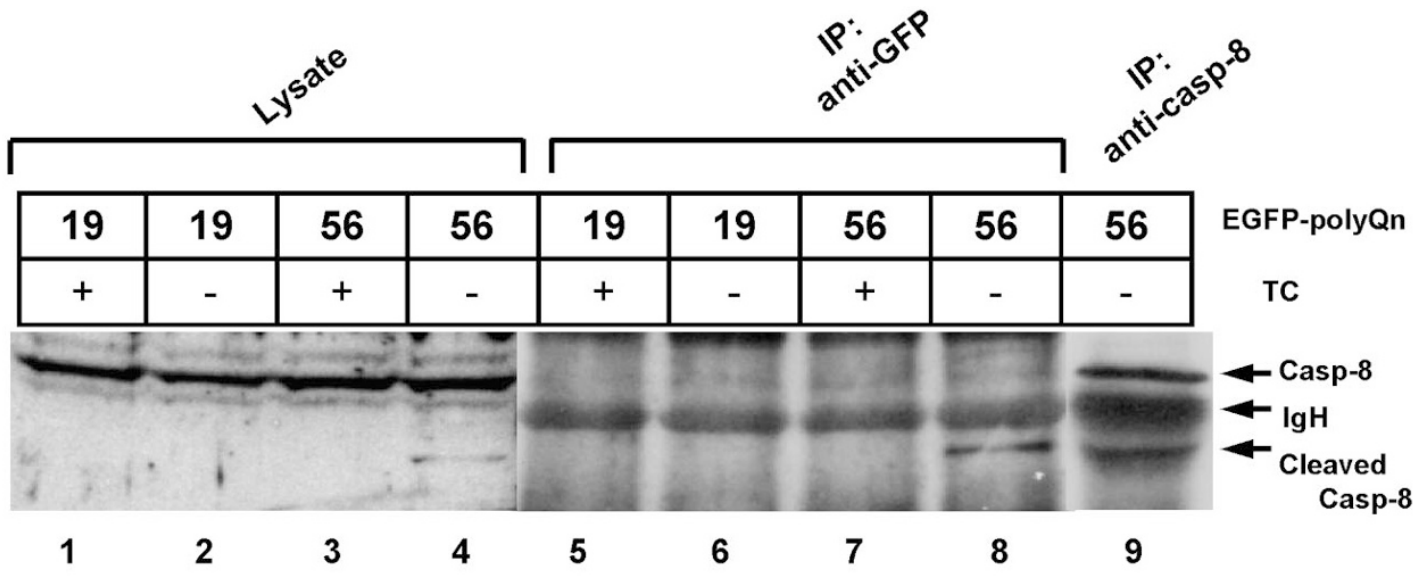

B

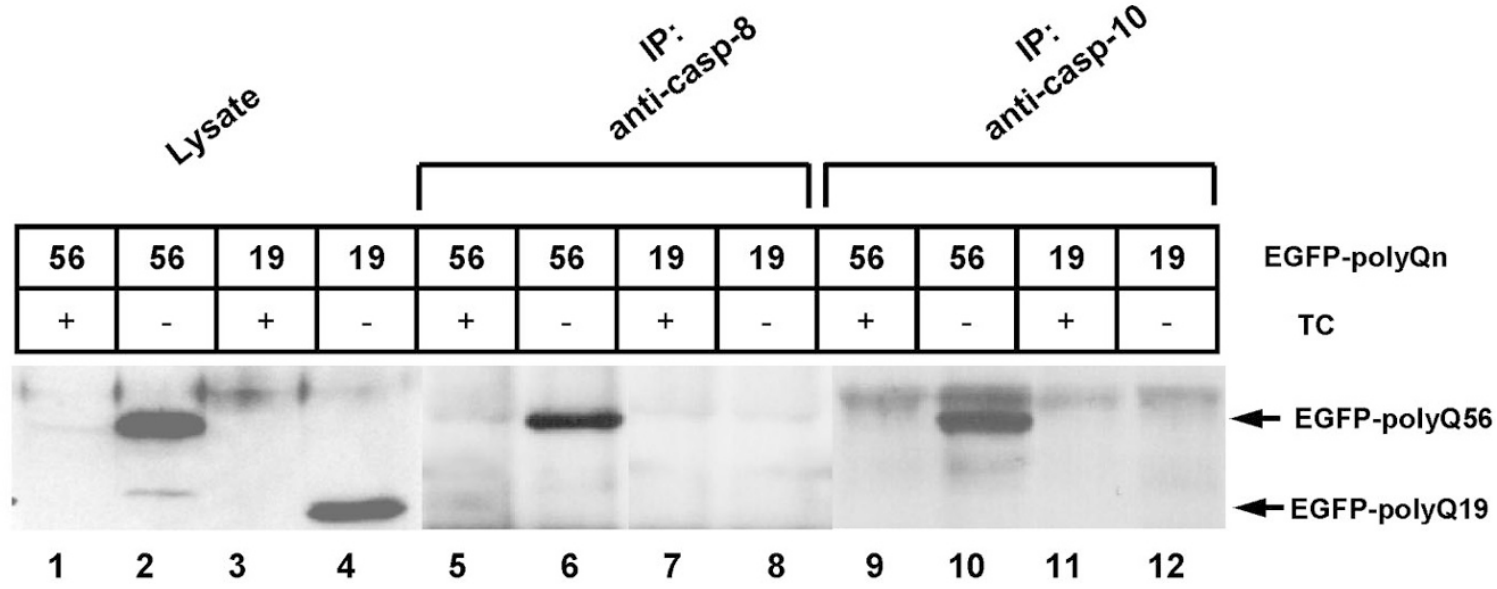

C

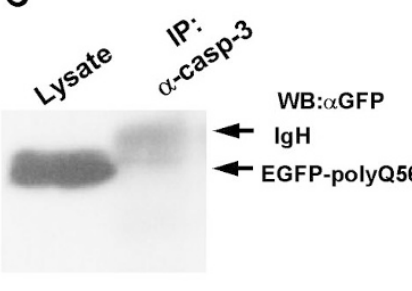<smiles>C=CC=C1CCCCC1</smiles>

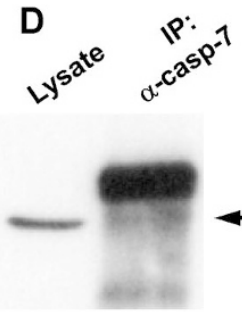

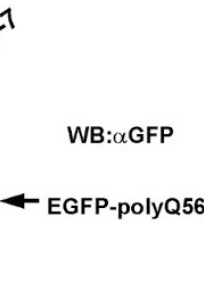

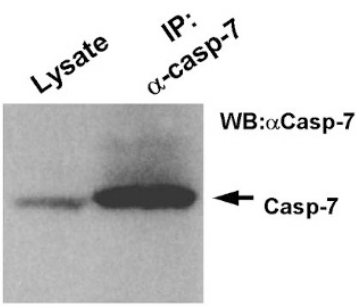

E

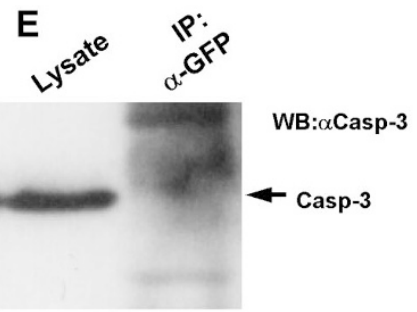

F

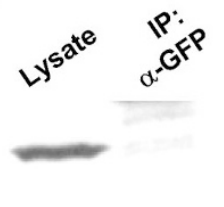

WB: $\alpha$ Casp-7

Casp-7
G

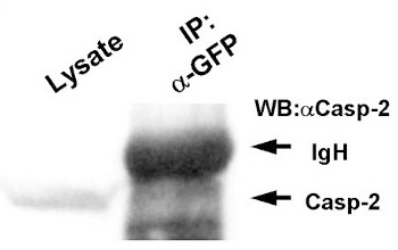

Figure 6 Interaction of extended polyglutamine with endogenous caspase-8. (A,B) IGROV-EQ19 or IGROV-EQ56 cells were cultured in the presence or absence of TC for 3 days. Cell lysates were then prepared and immunoprecipitated with the antibody indicated at the top of each panel. The immunoprecipitates $(\mathbf{A}$, lanes $5-9$, and $\mathbf{B}$, lanes $5-12)$ as well as aliquots of the original lysates $(\mathbf{A}, \mathbf{B}$, lanes $1-4)$ were analyzed by immunoblotting with the anti-caspase-8 (A) or anti-GFP (B) antibody. (C-G) Similar experiments were done with cell lysates prepared on day 3 from IGROV-EQ56 cells cultured in the absence of TC. The antibody used for immunoprecipitation is indicated at the top of each panel. Anti-GFP (C, D, left panels), anti-caspase-3 (C, right panel and E), anti-caspase-7 (D, right panel and F), and anti-caspase-2 (G) antibodies were used for immunoblotting 


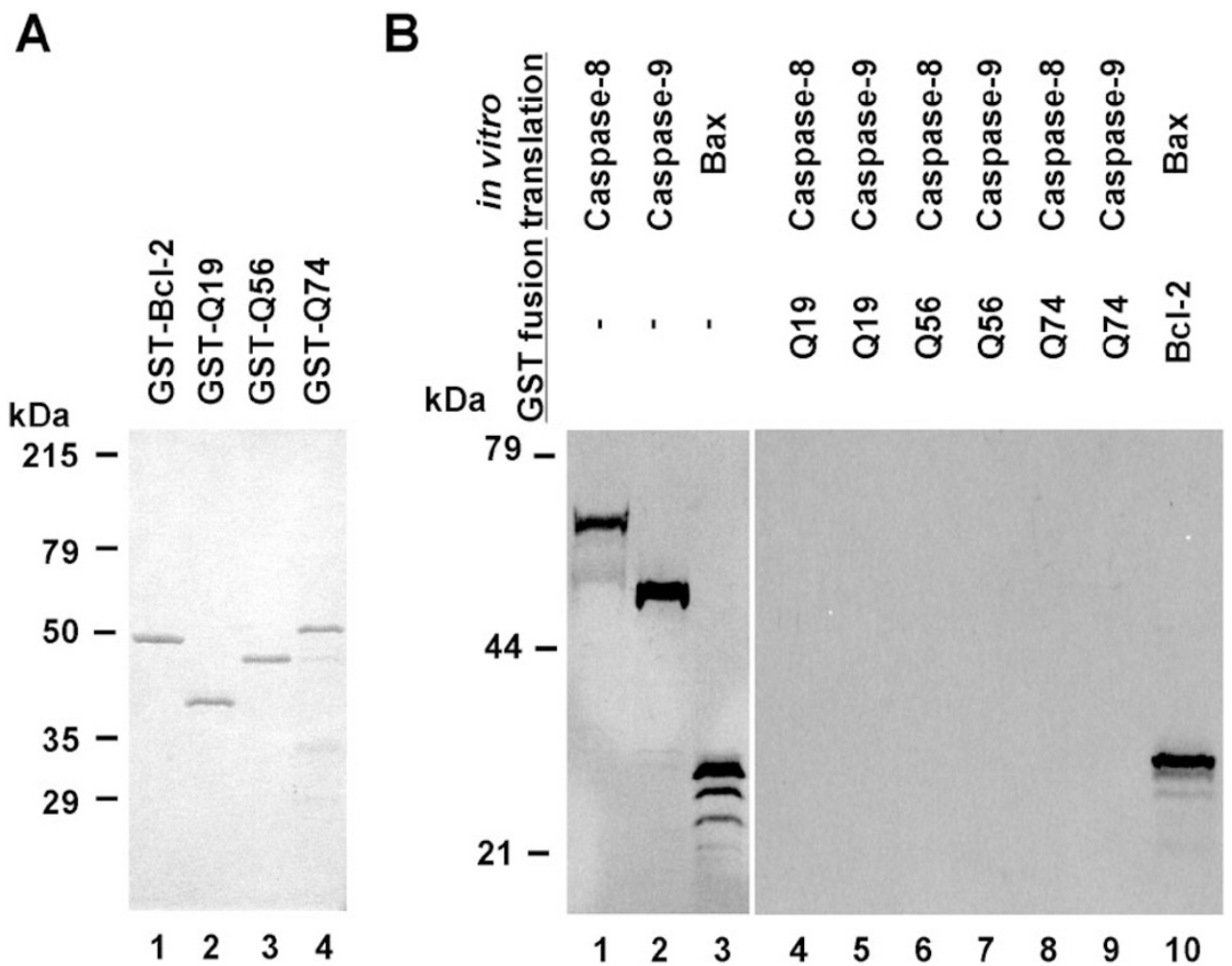

Figure 7 Possible indirect interactions between polyglutamine and caspases. (A) GST-fused Bcl-2 or polyglutamine was expressed in bacteria and purified. One microgram of each protein was stained with Coomassie Brilliant Blue after SDS-PAGE. (B) GST fusion proteins (10 $\mu \mathrm{g}$ ) were immobilized on glutathioneSepharose and incubated with $10 \mu \mathrm{l}$ of L-[ $\left.{ }^{35} \mathrm{~S}\right]$-methionine-labeled in vitro-translated proteins. After extensive washing, beads were boiled in Laemmli buffer. Eluted fractions were analyzed by SDS-PAGE and detected by autoradiography (lanes 4-10). One microliter aliquots of in vitro-translated proteins were also electrophoresed directly in the gel as a control (lanes 1-3)

Table 1 Inhibition of apoptosis by dominant negative caspase-8

\begin{tabular}{|c|c|c|c|c|}
\hline $\begin{array}{l}\text { Transfected } \\
\text { DNA }\end{array}$ & $\begin{array}{l}\text { Z- } \\
\text { VAD- } \\
\text { fmk }\end{array}$ & $\begin{array}{c}\text { Cells with } \\
\text { aggregates } \\
(\%)\end{array}$ & $\begin{array}{c}\text { Cells with } \\
\text { apoptotic } \\
\text { phenotype } \\
(\%)\end{array}$ & $\begin{array}{c}\text { (Cells with } \\
\text { apoptotic } \\
\text { phenotype/ } \\
\text { cells with } \\
\text { aggregates) } \\
(\%)\end{array}$ \\
\hline $\begin{array}{l}\text { pCl-FLAG } \\
\text { pFLAGCasp8(C/S) } \\
\text { pCl-FLAG }\end{array}$ & $\begin{array}{l}- \\
- \\
+\end{array}$ & $\begin{array}{l}50.7 \pm 5.1 \\
50.1 \pm 4.6 \\
44.3 \pm 5.5\end{array}$ & $\begin{array}{r}26.3 \pm 1.8 \\
13.0 \pm 2.3^{b} \\
9.8 \pm 3.8^{a}\end{array}$ & $\begin{array}{l}52.3 \pm 6.4 \\
21.7 \pm 5.5^{a} \\
26.3 \pm 6.9^{a}\end{array}$ \\
\hline
\end{tabular}

IGROV-EQ56 cells were transfected with plasmids as indicated, and the next day, the expression of EGFP-poly $Q_{56}$ fusion protein was induced by removing TC from the medium. Z-VAD-fmk $(50 \mu \mathrm{M})$ was added to some cells after transfection. Two days after induction, cells were stained with Hoechst33342. Green fluorescent cells were counted under a fluorescence microscope and classified according to the presence or absence of aggregates or nuclear apoptotic phenotype. At least 200 fluorescent cells were counted in each experiment. Results are means \pm S.D. of three independent experiments. ${ }^{\mathrm{a}} P<0.005,{ }^{\mathrm{b}} P<0.001$, vs $\mathrm{pCl}$-FLAG $t$-test

proteins interact indirectly via a third adaptor molecule, thus making a DISC-like complex. A candidate molecule would be FADD in the light of the recent report that truncated FADD was recruited by polyglutamine inclusions. ${ }^{10}$

The relationship between aggregate formation, particularly in the nucleus and induction of apoptosis still remains controversial. In some experiments, nuclear aggregation did not appear to be necessary for cell death. ${ }^{11,28}$ However, microaggregation that cannot be detected by observation under a microscope may induce caspase-8 (or -10) oligomerization and activation. It is also possible that extended polyglutamine induce both aggregate-dependent and -independent cell death. The latter may not be caspase-dependent.

In any case, it is not yet clear how polyglutamine forms aggregates exclusively in the nucleus, at least in some types of cells such as IGROV-1, 293, or PC12 (Figures 2 and $5 \mathrm{~A}$, and data not shown). At least, our GFP-tagged polyglutamine does not have a nuclear localization signal. In addition, further studies should address the question of whether polyglutamine and caspase-8 first bind each other in the cytoplasm and then enter the nucleus. In this case, the apoptotic process is triggered in the cytoplasm before polyglutamine enters the nucleus. The interaction is probably mediated by microaggregation or oligomerization of polyglutamine as discussed above. Alternatively, a small amount of nuclear caspase-8 interacts with polyglutaminemediated nuclear aggregates and then recruits more caspase-8. There have been several reports that demonstrate the nuclear localization of some caspases such as caspase-1, -2 , -3 , or -9 under certain circumstances. ${ }^{29-32}$

Recently, DAXX, first identified as a protein capable of binding Fas, was reported to regulate Fas-induced apoptosis from promyelocytic leukemia protein (PML) 
oncogenic domains. ${ }^{33} \mathrm{PML}$ also associates with ataxin-1, a causative molecule of spinocerebellar ataxia, type 1, which is one of the CAG-repeat diseases. ${ }^{34}$ Interestingly, DAXX has been reported to interact with caspase- 8 and -10 , at least in yeast two-hybrid analysis. ${ }^{33}$ Therefore, polyglutamine-mediated activation of these proteases may be regulated by DAXX. Several other proteins have been reported to co-aggregate with polyglutamine, including $20 S$ proteasome protein, molecular chaperones, and leucinerich acidic nuclear protein. ${ }^{35,36}$ Among these proteins, molecular chaperones such as Hsp40 or Hsp70 may play important roles in pathogenesis, since they have been reported to suppress polyglutamine toxicity both in Drosophila and cultured cells. ${ }^{37-40}$

Caspase- 8 has been suggested to have roles distinct from mediation of death receptor-induced cell death. Defective embryonic development in caspase-8 knockout mice seems to indicate that some effect other than cell death induction (perhaps growth stimulation) is mediated by caspase-8. ${ }^{15}$ Other evidence has shown that detachmentinduced apoptosis, also called anoikis, involves the activation of caspase- $8 .{ }^{41,42}$ Here we have demonstrated an additional caspase-8- and possibly -10-mediated apoptotic pathway induced by polyglutamine, where both caspases are autoactivated by co-aggregating with extended polyglutamine in the nucleus and then activate downstream caspases. This explains, at least in part, the toxic gain-of-function mechanism mediated by expanded polyglutamine.

Recently Ona et al. ${ }^{12}$ reported that the inhibition of caspase- 1 by a dominant-negative mutant of caspase- 1 delays the onset or slows the progression of $\mathrm{HD}$ in model animals. Since caspase- 1 is a proinflammatory rather than proapoptotic caspase, it is possible that this is an indirect effect of the inhibition of inflammatory responses rather than of the inhibition of apoptosis. In any case, this observation, together with ours using a dominant negative mutant of caspase-8, has potentially important implications for therapeutic intervention.

\section{Materials and Methods}

\section{Reagents}

Carbobenzoxy- Val-Ala-Asp -fluoromethyl ketone (z-VAD-fmk) was purchased from Peptide Institute Inc., Japan. Rabbit anti-caspase-3, -8 , and $\mathrm{Bcl}-2$ antibodies were kindly provided by $\mathrm{Dr}$. JC Reed. Monoclonal antibodies against green fluorescent protein (GFP) and caspase-9 was purchased from Medical \& Biological Lab., Japan. AntiFLAG and caspase-7 monoclonal antibodies were purchased from Sigma and Transduction Lab., respectively. Rabbit polyclona antibodies against caspase-2 and -10 (FLICE2) were from Santa Cruz Biotechnology and Millennium Biotechnology, respectively. The anti-human Fas monoclonal antibody $(\mathrm{CH} 11)$ was purchased from Medical \& Biological Laboratories, Japan.

\section{Generation of antibodies that specifically recognize cleaved forms of caspase-8 and -9}

Japanese white rabbits were immunized with $\mathrm{NH}_{2}$-CIPVETD-COOH or $\mathrm{NH}_{2}$-CSNPEPD-COOH peptides. These peptides contained the six amino acids that precede aspartic acid 374 of caspase- 8 and aspartic acid 315 of caspase- 9 , respectively, in addition to an amino-terminal cysteine residue for coupling to keyhole limpet hemocyanin. The rabbits were boosted six times with the immunizing peptides over an 8week period, and sacrificed at 10 weeks when titers against the immunizing peptide were $>1: 100000$ and $1: 10000$, respectively (determined by ELISA and defined as the maximal dilution giving a positive response, arbitrarily set at $\mathrm{OD}_{492}=0.2$ using the chromogenic substrate for horseradish peroxidase). The antisera, designated as anti-caspase-8 $8 \mathrm{C}$ and anti-caspase- $9 \Delta \mathrm{C}$ hereafter, were affinitypurified using SulfoLink Kits (PIERCE) in which the respective immunizing peptides were immobilized on agarose.

\section{Cell culture and transfection}

The human ovarian cancer cell line, IGROV-1, and its derivatives for inducible expression of polyglutamine were previously described. ${ }^{9}$ The human embryonic kidney cell line, 293, and human T-cell leukemia line, Jurkat, were cultured in Dulbecco's modified Eagle's medium and RPMI 1640 medium, respectively, supplemented with $10 \%$ fetal calf serum, $50 \mathrm{U} / \mathrm{ml}$ penicillin and $0.1 \mathrm{mg} / \mathrm{ml}$ streptomycin at $37^{\circ} \mathrm{C}$ in a humidified atmosphere of $5 \% \mathrm{CO}_{2}$ and $95 \%$ air. 293 cells $\left(2 \times 10^{6}\right)$ were transfected with a mixture of Effectene reagent (Qiagen), $3.5 \mu \mathrm{g}$ of FLAG-tagged and $1.5 \mu \mathrm{g}$ GFP-tagged vector. zVAD-fmk $(50 \mu \mathrm{M})$ was added during transfection in some experiments to enhance the expression level of transfected genes. Cell lysates were prepared 3 days after transfection using the following lysis buffer: $10 \mathrm{mM}$ Tris- $\mathrm{HCl}$ [pH 7.4], $150 \mathrm{mM} \mathrm{NaCl}, 5 \mathrm{mM}$ EDTA, $1 \%$ Triton X$100,1 \%$ NP40 and a cocktail of protease inhibitors.

\section{Plasmid constructs}

pEGFP-poly $Q_{19}$ and $p E G F P$-poly $Q_{56}$ were described previously. ${ }^{9}$ To produce $p E G F P$-poly $Q_{71}$, an Apal-Apal fragment carrying 71 repeats of polyglutamine was excised from pMY $1247^{5}$ and subcloned into pEGFP-C3 (Clontech). pGEX-polyQ constructs were made in pGEX5X-3 (Amersham Pharmacia Biotech) with DNA fragments amplified by PCR with primers located in the DRPLA gene, in which 7 amino acids at the $5^{\prime}$ end and 17 amino acids at $3^{\prime}$ end in addition to polyglutamine were encoded. cDNAs covering the entire coding region of human caspase- 6 and -9 were obtained by polymerase chain reaction coupled with reverse transcription (RT - PCR) with fetal brain mRNA (Clontech) and primers designed based on the reported sequences. They were then subcloned into the FLAG-tag vectors pcDNA3-FLAG or pCl-FLAG (kindly provided by Dr. S Takayama) to generate pCasp6-FLAG and pFLAG-Casp9, respectively. CDNA encoding the caspase-8 prodomain was amplified by RT-PCR as described above and subcloned into $\mathrm{pET} 15 \mathrm{~b} / \mathrm{Casp} 8$ (kindly provided by Dr. GS Salvesen), which encodes the amino acids from Ser217 to the $C$ terminus of caspase-8. The resulting cDNA encoding full-length caspase-8 was then excised and subcloned into $\mathrm{pCl}$-FLAG to generate pFLAG-Casp8. pFLAGCasp8(C/S) was created by the PCR overlap extension technique. ${ }^{18}$ Full-length and deletion mutants of caspase-3 (amino acids 1-175), caspase-8 (amino acids 1-374), and caspase-9 (amino acids 1-315) were generated by PCR, subcloned into $\mathrm{pCI}-\mathrm{FLAG}$ or pBluescript SK(Stratagene), and used for in vitro translation. They were also subcloned into pGEX5X-1 (Amersham Pharmacia Biotech) to produce glutathione S-transferase (GST)-caspase fusion proteins.

\section{Production and purification of GST-caspases}

To obtain GST-fused proteins, GST-caspases and GST-polyQ were expressed in $E$. coli strain BL21 (Novagen), except for $\mathrm{His}_{6}$-tagged 
caspase-8 by pET15b/Casp8 in E. coli strain BL21(DE3)pLysS (Novagen). GST-tagged and $\mathrm{His}_{6}$-tagged proteins were purified by affinity chromatography using glutathione-Sepharose 4B (Amersham Pharmacia Biotech) and Ni-nitrilotriacetic acid agarose (Qiagen), respectively, according to the manufacturer's instructions.

\section{Immunostaining and confocal microscopy}

To determine the subcellular localization of target proteins, cells were cultured on chamber slides (Nalge Nunc International). After induction of transfected genes, cells were fixed at $4^{\circ} \mathrm{C}$ for $1 \mathrm{~h}$ in $4 \%$ paraformaldehyde, permeabilized with $0.5 \%$ Triton $\mathrm{X}-100$ for $1 \mathrm{~h}$, and blocked for $1 \mathrm{~h}$ at RT in 5\% skim milk and $1 \% \mathrm{BSA}$ in $10 \mathrm{mM}$ Tris$\mathrm{HCl}(\mathrm{pH} 8.0), 150 \mathrm{mM} \mathrm{NaCl}$ and $0.1 \%$ Tween20. The slides were then incubated for $1 \mathrm{~h}$ with rabbit polyclonal antibodies recognizing caspase- 3 , caspase- 8 , caspase- $8 \Delta C$, caspase- $9 \Delta C$, caspase- 10 or $\mathrm{Bcl}-2$, and then with tetramethylrhodamine isothiocyanate (TRITC)labeled anti-rabbit immunoglobulin (1:20). A fluorescent image was obtained using a confocal microscope (Fluoview or GB-200, OLYMPUS, Tokyo, Japan).

\section{In vitro translation and binding assay}

The in vitro-translated proteins were prepared using the TNT-coupled reticulocyte lysate system (Promega) according to the manufacturer's recommendations. Ten microliters of the reaction mixture was used for Western blotting. For in vitro binding assays, $10 \mu \mathrm{g}$ of GST fusion proteins immobilized on glutathione-Sepharose were mixed with $10 \mu \mathrm{l}$ of $\mathrm{L}-\left[{ }^{35} \mathrm{~S}\right]$ methionine-labeled in vitro-translated proteins in $250 \mu \mathrm{l}$ of HKM solution (10 mM HEPES (pH 7.2), $142.5 \mathrm{mM} \mathrm{KCl,} 5 \mathrm{mM} \mathrm{MgCl}_{2}$, $1 \mathrm{mM}$ EGTA and $0.2 \% \mathrm{NP}-40$ ) for $2 \mathrm{~h}$ at $4^{\circ} \mathrm{C}$. Beads were washed four times before they were boiled in Laemmli buffer. Eluted proteins were analyzed by SDS-PAGE followed by autoradiography.

\section{Immunoprecipitation and Western blot analysis}

Two hundred micrograms of total protein was immunoadsorbed with the antibody against GFP, FLAG, caspase-3, $-7,-8$ or -10 for 6 h at $4^{\circ} \mathrm{C}$, and then with protein $A / G$ agarose (Santa Cruz Biotechnology) for $16 \mathrm{~h}$ at $4^{\circ} \mathrm{C}$. The immunoprecipitated pellets were washed four times with lysis buffer (see above) and finally resuspended in SDS sample buffer. The immunoprecipitates were subjected to SDS-PAGE and transferred onto a nitrocellulose membrane. Western blot analysis was performed as described previously with horseradish peroxidase-conjugated rabbit anti-mouse (for the detection of GFP and caspase-7) (DAKO) or goat anti-rabbit (for the detection of caspase-2, $-3,-8,-9,-10$ and cleaved forms of caspase-8 and -9) (Sigma) immunoglobulins. ${ }^{5}$ The proteins were visualized by using enhanced chemiluminescence Western blotting detection reagents (Amersham Pharmacia Biotech).

\section{Apoptosis assays}

IGROV-EQ56 cells were transfected with either pFLAG-Casp8(C/S) or a control vector pCl-FLAG. Sixteen hours after transfection, the expression of EGFP-poly $Q_{56}$ was induced by removing tetracycline (TC) from the medium. z-VAD-fmk $(50 \mu \mathrm{M})$ was added to some cells after transfection. Two days after induction, cells were stained with the DNA dye Hoechst33342 (1.25 $\mu \mathrm{M}, 10 \mathrm{~min})$. Cells expressing EGFPpoly $Q_{56}$ were scored as apoptotic when they had a pyknotic and/or fragmented nucleus. Apoptotic nuclei were counted in a blinded manner.

\section{Acknowledgements}

We thank Drs. JC Reed, GS Salvesen and S Takayama for antibodies and plasmids, and Dr. R Takahashi for helpful discussions. We are also grateful to A Asaka and $\mathrm{K}$ Higashijima for technical assistance and $\mathrm{K}$ Saito for manuscript preparation. This study was supported in part by grants for Brain Research, for Cancer Research and for Genome Research from the Ministry of Health and Welfare, a Grant-in-Aid for Scientific Research from the Ministry of Education, Science and Culture, and a Grant for Organized Research Combination System from the Science and Technology Agency, Japan.

\section{References}

1. The Huntington's Disease Collaborative Research Group (1993) A novel gene containing a trinucleotide repeat that is expanded and unstable on Huntington's disease chromosomes. Cell 72: 971-983

2. Nagafuchi S, Yanagisawa H, Sato K, Shirayama T, Ohsaki E, Bundo M, Takeda T, Tadokoro K, Kondo I, Murayama N, Tanaka Y, Kikushima H, Umino K, Kurosawa H, Furukawa T, Nihei K, Inoue T, Sano A, Komure O, Takahashi M, Yoshizawa T, Kanazawa I and Yamada M (1994) Dentatorubral and pallidoluysian atrophy expansion of an unstable CAG trinucleotide on chromosome 12p. Nat. Genet. 6: 14-18

3. Ross CA (1995) When more is less: pathogenesis of glutamine repeat neurodegenerative diseases. Neuron 15: 493-496

4. Thornberry NA (1998) Caspases: enemies within. Science 281: 1312-1316

5. Miyashita T, Okamura-Oho Y, Mito Y, Nagafuchi S and Yamada M (1997) Dentatorubral pallidoluysian atrophy (DRPLA) protein is cleaved by caspase-3 during apoptosis. J. Biol. Chem. 272: 29238-29242

6. Miyashita T, Nagao K, Ohmi K, Yanagisawa H, Okamura-Oho Y and Yamada M (1998) Intracellular aggregate formation of dantatorubral-pallidoluysian atrophy (DRPLA) protein with the extended polyglutamine. Biochem. Biophys. Res. Commun. 249: 96-102

7. Wellington CL, Ellerby LM, Hackam AS, Margolis RL, Trifiro MA, Singaraja R, McCutcheon K, Salvesen GS, Propp SS, Bromm M, Rowland KJ, Zhang T, Rasper D, Roy S, Thornberry N, Pinsky L, Kakizuka A, Ross CA, Nicholson DW, Bredesen DE and Hayden MR (1998) Caspase cleavage of gene products associated with triplet expansion disorders generates truncated fragments containing the polyglutamine tract. J. Biol. Chem. 273: 9158-9167

8. Ellerby LM, Hackam AS, Propp SS, Ellerby HM, Rabizadeh S, Cashman NR, Trifiro MA, Pinsky L, Wellington CL, Salvesen GS, Hayden MR and Bredesen DE (1999) Kennedy's disease: caspase cleavage of the androgen receptor is a crucial event in cytotoxicity. J. Neurochem. 72: 185-195

9. Miyashita T, Matsui J, Ohtsuka Y, Fujishima S, Okamura-Oho Y, Inoue T and Yamada M (1999) Expression of extended polyglutamine sequentially activates initiator and effectorcaspases. Biochem. Biophys. Res. Commun. 257:724-730

10. Sánchez I, Xu CJ, Juo P, Kakizuka A, Blenis J and Yuan J (1999) Caspase-8 is required for cell death induced by expanded polyglutamine repeats. Neuron 22 : $623-633$

11. Saudou F, Finkbeiner S, Devys D and Greenberg ME (1998) Huntingtin acts in the nucleus to induce apoptosis but death does not correlate with the formation of intranuclear inclusions. Cell 95: 55-66

12. Ona VO, Li M, Vonsattel JPG, Andrews LJ, Khan SQ, Chung WM, Frey AS, Menon AS, Li XJ, Stieg PE, Yuan J, Penney JB, Young AB, Cha JHJ and Friedlander RM (1999) Inhibition of caspase-1 slows disease progression in a mouse model of Huntington's disease. Nature 399: 263-267

13. Boldin MP, Goncharov TM, Goltsev YV and Wallach D (1996) Involvement of $\mathrm{MACH}$, a novel MORT1/FADD-interacting protease, in Fas/APO-1- and TNF receptor-induced cell death. Cell 85: 803-815

14. Muzio M, Chinnaiyan AM, Kischkel FC, O'Rourke K, Shevchenko A, Ni J, Scaffidi C, Bretz JD, Zhang M, Gentz R, Mann M, Krammer PH, Peter ME and Dixit VM (1996) FLICE, a novel FADD-homologous ICE/CED-3-like protease, is recruited to the CD95 (Fas/APO-1) death-inducing signaling complex. Cell 85: 817-827

15. VarfolomeevEE, Schuchmann M, Luria V, Chiannilkulchai N, Beckmann JS, Mett IL, Rebrikov D, Brodianski VM, Kemper OC, Kollet O, Lapidot T, Soffer D, Sobe T, Avraham KB, Goncharov T, Holtman H, Lonai P and Wallach D (1998) Targeted disruption of the mouse Caspase 8 gene ablates cell death induction by the TNF receptors, Fas/Apo1, and DR3 and is lethal prenatally. Immunity 9: 267-276 
16. Fernandes-Alnemri T, Armstrong RC, Krebs J, Srinivasula SM, Wang L, Bullrich F, Fritz LC, Trapani JA, Tomaselli KJ, Litwack G and Alnemri ES (1996) In vitro activation of CPP32 and Mch3 by Mch4, a novel human apoptotic cysteine protease containing two FADD-like domains. Proc. Natl. Acad. Sci. USA 93 $7464-7469$

17. Vincenz C and Dixit VM (1997) Fas-associated death domain protein interleukin$1 \beta$-converting enzyme 2 (FLICE2), an ICE/Ced-3 homologue, is proximally involved in CD95- and p55-mediated death signaling. J Biol. Chem. 272: 65786583

18. Ho SN, Hunt HD, Horton RM, Pullen JK and Pease LR (1989) Site-directed mutagenesis by overlap extension using the polymerase chain reaction. Gene 77: $51-59$

19. Li P, Nijhawan D, Budihardjo I, Srinivasula SM, Ahmad M, Alnemri ES and Wang $X$ (1997) Cytochrome $c$ and dATP-dependent formation of Apaf-1/caspase-9 complex initiates an apoptotic protease cascade. Cell 91: 479-489

20. Stennicke HR, Deveraux QL, Humke EW, Reed JC, Dixit VM and Salvesen GS (1999) Caspase-9 can be activated without proteolytic processing. J. Biol. Chem. 274: $8359-8362$

21. Srinivasula SM, Ahmad M, Fernandes A and Alnemri ES (1998) Autoactivation of procaspase- 9 by Apaf-1-mediated oligomerization. Mol. Cell 1: $949-957$

22. Yang X, Chang HY and Baltimore D (1998) Autoproteolytic activation of procaspases by oligomerization. Mol. Cell 1:319-325

23. Medema JP, Scaffidi C, Kischkel FC, Shevchenko A, Mann M, Krammer PH and Peter ME (1997) FLICE is activated by association with the CD95 death-inducing signaling complex (DISC). EMBO J. 16: 2794-2804

24. Hakem R, Hakem A, Duncan GS, Henderson JT, Woo M, Soengas MS, Elia A, de la Pompa JL, Kagi D, Khoo W, Potter J, Yoshida R, Kaufman SA, Lowe SW, Penninger JM and Mak TW (1998) Differential requirement for caspase 9 in apoptotic pathways in vivo. Cell 94: 339-352

25. Kuida K, Haydar TF, Kuan CY, GuY, Taya C, Karasuyama H, Su MS, Rakic P and Flavell RA (1998) Reduced apoptosis and cytochrome c-mediated caspase activation in mice lacking caspase 9. Cell 94: 325-337

26. Cardone MH, Roy N, Stennicke HR, Salvesen GS, Franke TF, Stanbridge E, Frisch S and Reed JC (1998) Regulation of cell death protease caspase-9 by phosphorylation. Science 282: 1318-1321

27. Wang J, Zheng L, Lobito A, Chan FK, Dale J, Sneller M, Yao X, Puck JM, Straus SE and Lenardo MJ (1999) Inherited human Caspase 10 mutations underlie defective lymphocyte and dendritic cell apoptosis in autoimmune lymphoproliferative syndrome type II. Cell 98: 47-58

28. Klement IA, Skinner PJ, Kaytor MD, Yi H, Hersch SM, Clark HB, Zoghbi HY and Orr HT (1998) Ataxin-1 nuclear localization and aggregation: role in polyglutamine-induced disease in SCA1 transgenic mice. Cell 95: 41-53
29. Colussi PA, Harvey NL and Kumar S (1998) Prodomain-dependent nuclear localization of the caspase-2 (Nedd2) precursor. A novel function for a caspase prodomain. J. Biol. Chem. 273: 24535-24542

30. Mao PL, Jiang Y, Wee BY and Porter AG (1998) Activation of caspase-1 in the nucleus requires nuclear translocation of pro-caspase-1 mediated by its prodomain. J. Biol. Chem. 273: 23621-23624

31. Krajewski S, Krajewska M, Ellerby LM, Welsh K, Xie Z, Deveraux QL, Salvesen GS, Bredesen DE, Rosenthal RE, Fiskum G and Reed JC (1999) Release of caspase-9 from mitochondria during neuronal apoptosis and cerebral ischemia. Proc. Natl. Acad. Sci. USA 96: 5752-5757

32. Zhivotovsky B, Samali A, Gahm A and Orrenius S (1999) Caspases: their intracellular localization and translocation during apoptosis. Cell Death Differ. 6 : 644-651

33. Torii S, Egan DA, Evans RA and Reed JC (1999) Human Daxx regulates Fasinduced apoptosis from nuclear PML oncogenic domains (PODs). EMBO J. 18: 6037-6049

34. Skinner PJ, Koshy B, Cummings CJ, Klement IA, Helin K, Servadio A, Zoghbi HY and Orr HT (1997) Ataxin-1 with an expanded glutamine tract alters nuclear matrix-associated structures. Nature 389: 971-974

35. Matilla A, Koshy BT, Cummings CJ, Isobe T, Orr HT and Zoghbi HY (1997) The cerebellar leucine-rich acidic nuclear protein interacts with ataxin-1. Nature 389: 974-978

36. Cummings CJ, Mancini MA, Antalffy B, DeFranco DB, Orr HT and Zoghbi HY (1998) Chaperone suppression of aggregation and altered subcellular proteasome localization imply protein misfolding in SCA1. Nat. Genet. 19: $148-154$

37. WarrickJM, Chan HY, Gray-Board GL, Chai Y, Paulson HL and Bonini NM (1999) Suppression of polyglutamine-mediated neurodegeneration in Drosophila by the molecular chaperone HSP70. Nat. Genet. 23: 425-428

38. Kazemi-Esfarjani P and Benzer S (2000) Genetic suppression of polyglutamine toxicity in Drosophila. Science 287: 1837-1840

39. Chai Y, Koppenhafer SL, Bonini NM and Paulson HL (1999) Analysis of the role of heat shock protein $(\mathrm{Hsp})$ molecular chaperones in polyglutamine disease. J. Neurosci. 19: 10338-10347

40. Kobayashi Y, Kume A, Li M, Doyu M, Hata M, Ohtsuka K and Sobue G (2000) Chaperones $\mathrm{Hsp} 70$ and $\mathrm{Hsp} 40$ suppress aggregate formation and apoptosis in cultured neuronal cells expressing truncated androgen receptor protein with expanded polyglutamine tract. J. Biol. Chem. 275: 8772-8778

41. Frisch SM (1999) Evidence for a function of death-receptor-related, deathdomain-containing proteins in anoikis. Curr. Biol. 9: 1047-1049

42. Rytömaa M, Martins LM and Downward J (1999) Involvement of FADD and caspase-8signalling in detachment-inducedapoptosis. Curr. Biol.9:1043-1046 